\title{
International entrepreneurship as a young field of scholarly inquiry and its relationship with the knowledge network of five related disciplines
}

\author{
Hamid Etemad ${ }^{1}$
}

Published online: 14 June 2016

(C) Springer Science+Business Media New York 2016

\section{Introduction}

The question of whether, or not, International Entrepreneurship (IE) is a field has confronted scholars from the early days of the field's emergence, sometime in early 1990s, although the very nature of emergence is its early fluidity. The scope of coverage and the wide geographical dispersion of both the scholars in, and practitioners of, the field of International Entrepreneurship may have also contributed to prolonging that fluidity. Furthermore, the very nature of early developments in International Entrepreneurship, in terms of differences in, and the diversities of the various local practice, processes, contexts and embeddedness may have contributed to slower development of the necessary corresponding concepts necessary for closure and consolidation of the core, if not the field, following its early emergence. Consider, for example, the core component in the name of the field- "entrepreneurship" and "international".

As a field of practice, the practice of international entrepreneurship in long-range trade routes, crossing regions of the ancient world, goes back to some 4000 to 6000 , if not 10,000 BCE. There is historic evidence pointing to the importation of domesticated animals by prehistoric Egypt and the ancient people of Sahara from Southwest Asia between 6000 and 4000 BCE. Rudimentary shipping was established by the fourth millennium BCE, and relatively organized traders were trading across the various regions of the ancient world, including North Africa, Egypt, Fertile Crescent and Indus Valley (Ancient India) before the second millennium BCE. The evidence of trade in obsidian, flint and precious stones, such as and Lapis Lazuli of Badakhshan (in the North East of preset Afghanistan), goes back to 2000 to 3000 BCE, all done by relatively small and independent trades. Phoenicians had become sea traders traveling across the Mediterranean and reaching Britain for sourcing tin in the Bronze age.

Hamid Etemad

hamid.etemad@mcgill.ca

1 McGill University, Montreal, Canada 
The history of the famed "Silk Road" points to more organized trade and exchange along the long-range trade route crossing many regions and spanning Asia and Europe, where the members of trading parties, or "Caravans" - an organized group of independent international traders - travelled from a few cities of the Middle Kingdom (i.e., The present China), such as the coastal cities of Dalian, Tianjin, Shanghai, Xiamen and Guangzhou, which were coastal production and marine trading centres, and also from other production centres in the interior, such as Wuhan, among many other centres of activities to the old capital city of Xian (centrally located and many roads to major cities) in the ancient China to prepare for a long trading journey westward. The history of such organized Caravans, the ancient counterparts of the modern trading delegations, also goes back to dates before the Common Era (BCE). They travelled on the longrange trade routes, a part of which was popularized as the famed Silk Road, stretching from the Middle Kingdom through the Russian Steppes (the present Central Asia), the ancient Persian Empire, a part of which is the present Iran, Babylonia and Sumeria to reach the present Europe and the predecessors of the Roman Empire. They faced many hazards and took much personal, professional and financial risks as they carried their valuable goods on horse- and Camels-backs and travelled on unsafe roads and passed through many no-man's lands exposing them to insecurity, organized pirates, thieves, robbers and hostile tribes. ${ }^{1}$ Yet, they pressed on and only stopped to rest in a "CarvanSara" (The temporary en-route stop-over and re-supplying station for the Caravans). They replenished their food and water supplies and provisions for animals and prepared for the next leg of the journey to the next Caravan-Sara on their way to reach a trading city to mostly exchange and barter trade in a few trading days, usually in the central Bazaars of the city (e.g., Doshanbe Bazaar in the capital city of the present Tajikestan, Doshanbe). Some of these remote Caravan-Saras were, or became, missions for the religious missionaries to expand their religious missions much later on. Similarly, some of old Bazaars and their attached (or nearby) Caravan-Saras functioned as massive centres for trade and commerce at the centres of the ancient cities in Iran, Syria, Asia Minor (the present Turkey), among others (Dana and Etemad 2000). Some of these Bazaars have endured over the years and are still standing and functioning well (e.g., The Grand Bazaar of Isfahan and Tabriz in central and Northwest Iran, respectively; and Grand Bazaars of Damascus and Istanbul - for more detailed discussion of bazaars, see Dana and Etemad 2000). In each bazaar, the independent entrepreneurs of the Caravan traded parts of their goods for the local supplies, mostly by barter, and carried the new combination to the next trading centre without prior knowledge of the nature of supply and demand there. They resembled the modern Kirznerian entrepreneurs who take the risks of educated guesses in arbitraging across markets.

Caravan memberships were also fluid. Some stopped in certain cities, some joined to reach the next city and some remained with the caravan and continued on the rest the trading route. Eventually, the caravan would reach its final destination (somewhere in the present Europe) and would prepare to reverse course with new supply of European goods to travel back to their origins in China or the Far East. They were true international entrepreneurs in terms of pro-activeness, innovativeness (e.g., taking novel products of one region for sale in another), market orientation and risk taking. Their decisions bore inherently high risks due to paucity, if not lack of, information,

\footnotetext{
${ }^{1}$ Some Caravans had their own security details to defend them against hazards.
} 
when it came, for example, to selecting the type and quantity of goods from China, India, the Persian Empire or other regions for trading them elsewhere partially or fully elsewhere. The trip itself posed immeasurable hazards and risks. In short, a form of entrepreneurship with international engagement has been present and practiced for a long time and has evolved and adapted to environmental change over time.

The purpose of the above description was not a cursory review of historical entrepreneurial international trade and the prevailing infrastructure supporting it in the past, going back to before the common era (BCE). However, it aimed to demonstrate that the actual practice of international entrepreneurship, or entrepreneurial internationalization, as a recognized field of practice has had a long historical standing going back to the ancient times (for a longer discussion, see Etemad 2004a). Although some of that historical knowledge has been forgotten and their lessons are lost over the years, the persistent existence of IE as a field of practice is beyond question. With the risk of information decays about the past practices, and the contemporary emphasis on short historical horizons, it seems safe to suggest that the international entrepreneurs of the past did not worry whether their rich range of practice were considered as a "field" or not. They continued their practice in spite of adversities facing them, possibly inadequate recognition of their profession and entrepreneurial efforts by the court or the nobility of the time in different countries and regions. They were entrepreneurs and traded internationally in the true sense of the word. In the various historical documents, their practice was attributed to international traders. They even preceded the term "entrepreneur or entrepreneurship".

In comparison to the much older field of practice, the scholarly counterpart of that field is relatively young and contemporary. The origin of the term entrepreneurship is attributed to the French Economist, Jean-Baptist Say, defining his contemporary French wine trades as entrepreneurs in early eighteenth century-not international entrepreneurs - although they sold French wines nearly everywhere in the region. Richard Cantillon was the scholar who publicized and wrote about entrepreneurship in the seventeenth and eighteenth century. However, even after more than 200 years, there is no consensus on the definition of what constitutes entrepreneurship as it has continually shadowed the evolving practice by the contemporary entrepreneurs of the time. The definition, and more importantly the true functioning of entrepreneurs, has yet to consolidate, and there will be evolving definitions as entrepreneurs innovate, adopt advancing innovations or change their entrepreneurial practice to fit their environment and markets. Does this state of fluidity, or flux, is a ground for questioning entrepreneurship?

Aside from the historical information, our documented modern knowledge of entrepreneurship, and international entrepreneurship by extensions, is less than three centuries old. International economics and international trade covered some of the associated functions and tasks within the context of the firm as black box, but without entrepreneurs at the helm. The institution of the "entrepreneurial firm", where the entrepreneur(s) is embeddedness in a form of organization, called "the firm" for ease of use, is rather young, if not contemporary. Then, should we expect the knowledge network $^{2}$ reflecting that practice to be as well-consolidated as that of the much older fields of scholarly inquiry?

\footnotetext{
${ }^{2}$ For the evidence of International Entrepreneurship Knowledge Network, see Etemad and Lee (2003).
} 
In favour of time and space, we will not explore the historical pedigree of the term international sharing parts of its heritage and core knowledge with allied fields, including international economics and trade, international relations, barriers to and incentives for trade and trade regulations, among others. It suffices to say that developments underlying the term international have broadened and evolved over the years and have become as rich and diverse, if not multi-purpose and multi-context, as its companion concepts of "entrepreneur" and entrepreneurship. Again, our historical perspectives have decayed, if not lost. Consider for example that the quest for establishing a modern free trade area under the Trans-Pacific Partnership (TPP) agreement is seemingly a recent innovative initiative, but it is not new. A similar arrangement prevailed in large regions of the world, including the ancient Mesopotamia (Presently, Iraq), Middle East, Parts of present Iran and Asia Minor (presently, modern Turkey) before the advent of nation states that raised protective walls around the sovereign nations. Conceptually, TPP will be taking us back to the ancient history's "square one"-i.e., only trying to achieve what was practiced a long time ago. In light of the long historical developments, and certainly the fluidity of and dynamism of both international and entrepreneurship over the years, due to the evolving and rich practice that has generally been ahead of their scholarly counterpart of those practices, it seems somewhat premature to apply measures of a field applying to the older and scientific fields to determine if a dynamic and a young field has emerged and consolidated towards a unified field, especially when a highly dynamic human proclivity (and endeavour), such as entrepreneurship, is strongly involved. Unless we accept a looser and more tentative linkage between the ever-evolving practice and its scholarly counterpart than those of sciences and older fields, the scholarly field of International Entrepreneurship is bound to remain in a dynamic state of evolution and somewhat behind the practice. The lag between the state of practice and the scholarly field is due to the very nature of entrepreneurship and the intensifying competition, where entrepreneurs will continually have to search for, and use, ever-advanced and more advantageous generation of innovative practices, procedures, and strategies, which the field aspires to reflect. For some scholars, such state of affairs is not an easy scholarly feeling. Ironically, when scholars research and publish broadly the essence of the previous, or prevailing, generation of an innovative or potent practice (of technology, strategy, competitive advantage, etc.), it reduces the competitive, entrepreneurial and strategic potency of that generation as a better understanding by scholars and practitioners that enable aspiring rival entrepreneurs to emulate and improve upon them to gain competitiveness. While this remains as the very essence of the phenomena, the need for the deployment of a more potent generation is necessitated, if the prevailing state of advantages practice is to be maintained.

\section{Back to the earlier question: Is international entrepreneurship a field?}

Abstracting from the nuances of above discussion, a major aim of this issue, and especially this editorial note, is to revisit the question of "if International Entrepreneurship has become a field? Substantive research is providing strong evidence that International Entrepreneurship has indeed become a young field of its own and it is not a subsidiary extension of one, or a few, related fields, and thus it puts the question to 
rest. From a positive point of view, questioning the state of a field forces the dedicated scholars to that field to use more prudent approaches and vigorous methodologies to avoid further questioning and drive to towards consolidation of the field's core knowledge as soon as possible. However, persistent questioning may discourage younger scholars from taking up the challenging issue of the field. This journal has adopted a balanced approach in order to further advance the development of International Entrepreneurship, or Entrepreneurial Internationalization (Etemad 2005), and its supportive disciplines, as a field of scholarly inquiry, yet encouraging rigorous scholarship to add to the dynamism, evolution and richness of research.

As a result, the next section of this editorial is dedicated to the re-examination of that existential question in relation to the findings of the next article, dealing with the same question, appearing after this editorial. The highlights of the three other articles related to and expanding upon a particular aspect of the field will follow.

The seminal article of Oviatt and McDougall (1994) pointed to the internationalization of new ventures (INVs) by entrepreneurial, smaller and younger firms (i.e., new ventures) and signalled the need for the beginning of a new stream of research, apart from the field of International Business, and possibly signalling the emergence of new field of scholarly inquiry concerning a new breed of firms in $1994 .^{3}$ Contrary to the received International Business theories, suggesting that smaller and younger firms would start their path of growth at home before venturing into international markets for further growth, Oviatt and McDougal article documented the case of new ventures internationalizing at a young age, if not from inception. These authors defined INVs as "Business Organizations that, from inception, seek to derive a significant competitive advantage from the use of resources and sale of outputs in multiple countries" (Oviatt and McDougall 1994: page 49). They also pointed out the need for a new theory addressing the internationalization of such INVs. The noteworthy point is that these business organizations were multi-country and multi-faceted institutions dealing with multi-contexts from early on in their lives, if not from the beginning, which would require certain knowledge and expertise, possibly ambidextrous organizational structure at both ends of their supply chain and value net from their starting point in order to access resources (at the upstreams of their supply chain) and also sale of outputs (at the downstreams of their value nets) in multiple country markets. The very nature of these organizations differed from their traditional counterparts prevailing at the time. Although Welsh and Loustarinen (1993) had pointed to outsourcing from international sources (i.e., "Backward or Inward" Internationalization) earlier on, it was for gaining incremental competitiveness at home, possibly through collaborative arrangements and strategic alliances, but not in relation to the traditional forward internationalization (i.e., "Outward or Forward Internationalization), even though it could expedite it inadvertently. Among other differences, these new ventures required a strong set of international capabilities and international orientation(s) from the start to make the necessary arrangement for accessing both resources and for establishing productive presence in multi-country markets in a relatively short time period after their founding. They were certainly innovative, proactive, risk taking and not a typical start-up striving to grow and survive at home. For example, a typical new venture, or start-up, finances its

\footnotetext{
${ }^{3}$ McDougal and Oviatt's contribution was recognized by the Academy of International Business (AIB), and their 1994 article won the 1990's decade award.
} 
growth mostly through local and regional angels, and venture capital and concentrates first on the most promising market segment at home before attempting other segments and international markets. Such differences in the starting point and early path of growth between those of INVs and their traditional counterpart would likely lead to a different starting point and evolutionary paths of growth and internationalization, each of which would require its own associated theoretical explanation of the phenomena, if not requiring a new theory.

Nearly a year earlier, Rennie (1993) had published an article, based on a McKinsey Consulting's survey report (1993), pointing to the international activity of a large portion of smaller Australian firms and called them "Born Globals". Although he did not propose a theory, he suggested that those smaller firms did not seek growth and maturity at home before venturing into far and distant international markets. In contrast to the prevailing theories at the time, these Born Global firms had neither followed the extant traditional theory, nor the practice of their larger Australian counterpart. They had deliberately rushed into international markets at early stages of their life cycle. Such practices were both deviations from internationalization theories and challenges to the prevailing practice by larger firms at the time.

Knight and Cavusgil (1996) concurred with Rennie and suggested that Born Globals posed a challenge to traditional internationalization theory. In a later publication, Knight and Cavusgil (2004) defined Born Globals as "entrepreneurial start-ups that, from or near their founding, seek to derive a substantial portion of their revenue from the sale of products in international markets". Although this definition shared important underlying concepts with that of Oviatt and McDougall (1994), it did not explicitly refer to international sourcing of resources. This important difference, notwithstanding both of these similar business organizations, differed significantly from the traditional institutions that concentrated on their relations with domestic buyers and suppliers before attending to their international counterparts. They had formed the institutions on which traditional internationalization theory was based.

Although these definitions have been revised and evolved to reflect the dynamic characteristics of INVs (Oviatt and McDougall 1994, 1995) and Born Globals, their pattern of internationalization has consistently and substantively differed from their counterparts. These differences pointed clearly to the recognition of their fundamental structural and strategic differences and their potential impacts on the path of their internationalization. Further research necessitated the need for a different theory, if not a new discipline, capable of thoroughly characterizing them and possibly building a theory based on their multi-context and multi-faceted foundations from the beginning. ${ }^{4}$

The historical annals of science indicate that when a newly discovered, or emerging, phenomenon cannot be explained by the prevailing theories of the time, requiring an alternative explanation or theory, the proponent of the old theory first question the necessity, even the legitimacy, of the emerging, or the newly proposed theory, and its plausible explanation in terms of questioning its characteristics for accepting it as the theory - e.g., the extent of rigour, sound assumptions, prudent methodology and clear differentiation in spite of its explaining power of the new phenomena. This state of

\footnotetext{
${ }^{4}$ In fact, the ontological view of the traditional internationalization theory suggests the need for a theory to clearly explain relations when the "nature of being, becoming, existence or reality as well as the basic categories of being and their relations," especially when the phenomena clearly deviate from what used to be.
} 
discomfort would likely continue for some times, before the new theory establishes strong roots and followings. The question of a need for a new theory, or whether it should not be a subset, or modification, of the older theory also lingers for some time. Similarly, the traditionalists would persistently and legitimately ask if the newly emerging theory (or its associated disciple) has the necessary theoretical core, prudent principal assumptions and analytical rigour to be considered as an acceptable theory, mostly not offering alternatives pathways or suggestions, by which the new theory could remedy its actual or perceived weaknesses, possibly prolonging its evolutionary development toward earlier perfection and completeness.

As briefly stated earlier, in response to question of "is International Entrepreneurship a field?", this editorial suggests a resoundingly positive answer. This answer is supported by the findings of the first article in this issue co-authored by Vinciane Servantie, Matthieu Cabrol, Gilles Guieu and Jean-Pierre Boissin in their article entitled as "Is International Entrepreneurship a Field: A Bibliometric Analysis of the literature (1989-2015)?". From a large number of (more than 1500) scholarly articles published on International Entrepreneurship topics, the first article had only a selective and restrictive sample for its thorough bibliometric study. Yet, this sample included 567 articles, authored and co-authored by more than 700 authors, affiliated with more than 30 universities in more than 20 countries, and excluded editorials and book chapters. ${ }^{5}$ The findings of this article point to broad and expanding knowledge network in international entrepreneurship published in some 112 peer-reviewed journals synthesizing more than 42,000 citations of nearly 16,000 different references. Similarly, more than 20 peer-reviewed journals have published cohesive themes in special issues about different aspects of International Entrepreneurship up to mid-2015. ${ }^{6}$ Collectively, this intellectual core in International Entrepreneurship strongly suggests a positive answer to the above question. Furthermore, it should come as no surprise that the core of this field is multi-disciplinary and includes at least five coherent, independent (of IE) and well-established clusters of theoretical bodies of knowledge, most all of which were not commonly considered as the supporting fields or theories of the traditional internationalization theories, and thus they differentiate International Entrepreneurship from other allied fields. The title of each of the five clusters represents an IE-related knowledge network of the named discipline. They are schematically shown in Fig. 2 of the paper and are listed below:

Cluster 1: Internationalization (the traditional stage and process theories of internationalization)

\section{Cluster 2: International New Ventures (INVs)}

\footnotetext{
5 This prudent selection criterion excluded a large number of peer reviewed articles appearing in cohesive collections such as edited book volumes and handbooks. Therefore, the selected sample of 567 articles included in the analysis under-represents the scope and strength of the field. For example, collections edited by IE scholars such as Dana (2004), Etemad (2013), Etemad et al. (2013, 2004b, 2016), Etemad and Wright (2003), and Wright (1999), Jones and Dimitratos (2004), among others, present an impressive number of additional articles that were also excluded from the bibliographic analysis of the first article. Therefore, the findings of the bibliometric examination are very conservative giving more credence to its analysis and consequent findings. ${ }^{6}$ Etemad and his collaborators alone had guest edited about 10 special issues of various journals on International Entrepreneurship, including the Canadian Journal of Administrative Sciences, Journal of Global Focus (2), Small Business Economics, International Managements Review, Management International Review, Journal of International Entrepreneurship, among others.
} 
Cluster 3: Born Global Firms and Networks

Cluster 4: The Resource-Based View (RBV) of the Firm

Cluster 5: Conceptualization and Synthesis

Similarly and as reviewed earlier, the business organizations of International Entrepreneurship have differed from their traditional counter parts in their multi-contexts (i.e., multi-markets and international sourcing) in addition to their multi-disciplinary orientation, while drawing on the multi-facets of their overall multi-environments for deploying advantageous capabilities and resources. Equally likely is that their operating orientation(s) and organizational structure(s), among others, have given these organizations access to resources from international suppliers and have enabled them to establish their market presence in international markets, possibly through collaborative arrangements, from inception (even before formal founding), which also differentiate them from typical start-ups.

\section{Highlights of the last three articles of this issue}

The third article included in this issue relates not only to the first one, but it also provides a vivid example of entrepreneurial internationalization (e.g., see Etemad 2005), where four domestic competitors in the Brazil's competitive fruit industry cooperate to internationalize successfully. This is also a form of "coopetition" that benefits the participants by cooperating on some aspects while competing on others. Such cooperation (or coopetition) is also at the intersection of at least two of the clusters identified by co-citation analysis in the first article on aspects of international entrepreneurship (please see endnote 5 of this note and the first article for the list and the subject matter of the five clusters), namely, at the intersection and interaction of Networking (a part of Cluster 3) and Internationalization (Clusters 1). This article, co-authored by Yakara Vasconselos Pereira Leite, Walter Fernando Araujo de Moraes and Viviane Santos Salazar, is entitled as "Expression of Relationship Networking in International Entrepreneurship". Briefly, the article documents the power of cooperation and networking amongst competitors for mobilizing increasingly beneficial resources, including information, and building trust amongst previous competitors for internationalizing successfully in a complex and competitive industry. The authors interviewed some 30 managers and developed a rich longitudinal view of the industry and four firms cooperating in the form of both horizontal and vertical networking with their buyers and suppliers. Such functional networking and cooperation positively affected their collective state of strategic information, which in turn enabled them to better respond to international demand and to the needs of their customers. It also affected their view of risks associated with international markets and internationalization, as they shared information and built trust amongst the cooperating firms.

Based on their research, the authors argue that networks can also bring intangible resources (in addition to the tangible ones) resulting in competitive and strategic advantages over not coopering rivals. They also suggest that the development and deployment of social networks, especially specialized and focused networks (e.g., those concentrating on international market opportunities, risk-mitigation and access to incremental resources, among other critical functions), are likely to yield handsome 
benefits for all involved in agricultural industry, where time is of the essence due to the perishability of agricultural products and fruits. Significant implications of this longitudinal research in the competitive agricultural industry in the context of emerging economies are the following: (i) Cooperation and networking do not happen by chance and without efforts; one has to cultivate and nurture them, especially in social networks over time; (ii) the overall benefits of establishing cooperation, collaboration and networks outweigh their costs; (iii) cultivating, and also extending networks, horizontally and vertically, require a strategic approach and longer term perspective; and (iv) cooperation with immediate competitors (e.g., those competing in the immediate domestic and regional markets) may enable higher competitiveness for entry into more competitive national and international markets.

The fourth article, authored by Tebago Rahaba Ngoma, is entitled as "It is not whom you know, it is how well you know them: Foreign Entrepreneurs building close guanxi relationships". This article relates to relation-making and network-building aspects of International Entrepreneurship, and the previous articles, by foreign entrepreneurs in a complex environment such as that of China. In such complex, collectivist and unfamiliar environments, where socio-cultural and institutional distances from their familiar counterparts at home are large, foreign business organizations and international entrepreneurs face higher risks and costs of entry and lower chances of successful operations. In terms of transaction costs concept, the initial transaction costs of operating in such distant environments are likely to outweigh their benefits in the absence of already-established relations, at least in the short run. The higher transaction costs and risks are in part because of many aspects of the complexity of the environment that are mostly implicit and intangible and their mastery by foreigners and foreign organizations require much efforts, time and possibly long first-hand interactions.

The above higher costs have been recognized by scholars collectively from different perspectives. For example, Hymer $(1960,1976)$ referred to them as the "liability of foreignness". Johanson and Vahlne (1977) suggested the need for developing "experiential knowledge" and "learning" Johanson and Vahlne (1990), whereby a foreigner would immerse himself in the environment in order to learn about, and internalize, socio-cultural attributes, especially the implicit and intangible aspects, to mitigate associated costs and risks. The scholars of institutional environment have related the higher costs to larger institutional distances (e.g., see Scott 1987 and Tolbert and Zucker 1999). Later-on, Johanson and Vahlne (2003) attributed the higher costs and risks to "the liability of outsidership", where one's network position would be relatively distant and weak for overcoming such large distances and liabilities. Even for the Chinese nationals, their positions and connections in functional and social networks are well recognized and the term "guangxi" summarily refers to the position and strength of such relations, connections and their benefits related to cultivating relations, especially in social network for intangible benefits. In this article, the author addressed the concept of guangxi and explored how foreigners and SMEs could cultivate guangxi to reduce their "distance" and overcome "foreignness", "outsidership" liabilities and their associated difficulties. The article reports that the familiar and much researched concept of "trust", and its affective and cognitive components, can ameliorate the situation facing foreign firms and international entrepreneurs. This article's analytical approach points to alternative ways for creating, cultivating and strengthening connections and relations. It also examined ways for building trust for not only reducing, if not 
overcoming, the adverse effects of foreignness, but also using guangxi relations to cultivate increasing social capital and network advantage.

The final and the fifth article of this issue, authored by Peerayuth Charoensukmongkul, is entitled as "The interconnection between bribery, political network, government supports and their consequences on export performance of small and medium enterprises in Thailand". This article complements the three articles preceding it. It explores the impact of interrelations amongst the broad aspects of ethical, institutional and political relations with exporting in Thailand. Research suggests that general government support stimulates exports and exporters and policy-makers encourage non-discriminatory support for exporting efforts, where all eligible exporters can qualify to receive fair support, regardless of their political connections. Such supports could cover a wide range of direct and indirect, but transparent and criteriabased, assistance in terms of direct subsidies, rebates of certain levies for exported goods and subsidized services as well as indirect assistance (e.g., funding of export-oriented research of universities, national research laboratories, among others) for internationalization in general and exports in particular. In contrast, bribes as quid-pro-quo understanding for receiving support is viewed with disdain as in many countries and is outright illegal and indictable criminal offence in others. Similarly, payments for attaining political connections to get support are equally illegal. However, a combination of unscrupulous practices, endemic corruption and institutional weakness may create conditions that tolerate bribery for receiving political and financial favours.

The author of this article sets to explore the relationship among bribery, political networks (connections) and government support and export performance of small and medium-sized enterprise in Thailand. A survey of 170 informants from companies that had joined a trade exhibition in Bangkok formed the data for analysis. Consistent with other research findings, the author found a strong association between governmental support and export performance. Disturbingly, however, the author also found a strong association between the extent of and entrepreneurs' political network and extent of bribery, in which entrepreneurs were engaged, and the governmental support they received. The author also observes that the extent of bribery and corruption of government officials in emerging economies are problematic and need serious monitoring to avoid unfair treatment of ethical and honourable firms aspiring to export.

In summary, the introductory discussion pointed to the complementary components of International Entrepreneurship. As a field of practice, entrepreneurial internationalization, or International Entrepreneurship, enjoys a long and well-established track record. The rigorous bibliographic analysis of a restrictive sample of 567 International Entrepreneurship-related articles in peer-reviewed journals pointed to the presence of a strong knowledge core of International Entrepreneurship at the intersection of the five established knowledge networks listed previously and well-discussed in the second paper of this issue, which in turn suggest that International Entrepreneurship is a strong multi-disciplinary and multi-context field of scholarly inquiry. Consistent with and related to the above article, the next three articles explored the interrelationship between relation building and networking aspects, possibly through collaborative arrangements and strategic alliances, and also various types of relations, including guangxi, of entrepreneurs and firms studied in Brazil, China and Thailand. Each article advanced questions for future and further research on the topics of the article in particular and the theme of International Entrepreneurship in general. Naturally, the journal encourages 
scholars to take-up the challenges of broadening and deepening the research themes and topics presented in this issue.

\section{References}

Dana LP (ed) (2004) The hand book of research in international entrepreneurship. Edward Elgar Publishing, Cheltenham

Dana LP, Etemad H (2000) The bazaar economy. In: Dana LP (ed) Economies of the Eastern Mediterranean: economic miracles in the making. World Scientific, Singapore, pp 27-45

Etemad H (2004a) Internationalization of small and medium-sized enterprises: a grounded theoretical framework and an overview. Canad J Admin Sci 21(1):1-21, Spring 2004

Etemad H (ed) (2004b) International entrepreneurship in small and medium-sized enterprises: orientation, environment and strategy. Edward Elgar Publishing Ltd., Northampton, Mass. and Cheltenham, UK, Fall 2004. Its e-book version is found at: http://www.elgaronline.com/view/9781843761945.xml

Etemad H (2005) Entrepreneurial Internationalization or International entrepreneurship. Manag Int Rev 45(3):3-13

Etemad H (ed) (2013) International entrepreneurship in small and medium-sized enterprises from emerging markets. Edward Elgar Publishing Ltd., Northampton, Mass. and Cheltenham, UK, June/July 2013. Its recently e-book version can be accessed at: http://www.elgaronline.com/view/9781843761945.xml

Etemad H, Lee Y (2003) The knowledge network of international entrepreneurship: theory and evidence. J Small busin Econ 20(1):5-23, January/February 2003

Etemad H, Wright RW (eds) (2003) Globalization and entrepreneurship: policy and strategy perspectives. Edward Elgar Publishing Ltd., Northampton, Mass. and Cheltenham, UK, July 2003. Its e-book version is available at: http://www.elgaronline.com/view/184376024X.xml

Etemad H, Madsen TA, Rasmussen E, Servais (eds) (2013) Current issues in international entrepreneurship. Edward Elgar Publishing Ltd., Northampton, Mass. and Cheltenham, UK, November/December 2013. Its e-book is at available at: http:/www.elgaronline.com/view/9781781953419.xml

Etemad H, Denicolai S, Hagen B, Zucchella A (eds) (2016) The change in the global economy and the future of international entrepreneurship. Edward Elgar Publishing Ltd, Northampton

Hymer SH (1960) The international operations of national firms: a study of direct foreign investment, $\mathrm{PhD}$ Dissertation, Massachusetts Institute of Technology

Hymer SH (1976) The international operations of national firms: a study of direct foreign investment. MIT Press, Cambridge

Johanson J, Vahlne JE (1977) The internationalization process of the firm: a model of knowledge development and increasing foreign market commitments. J Int Busin Stud 8(2):23-32

Johanson J, Vahlne JE (1990) The mechanism of internationalisation. Int Market Rev 7(4):11-24

Johanson J, Vahlne JE (2003) Business relationship, learning and commitment in the internationalization process. J Int Entrepreneur 1(1):83-101

Jones MV, Dimitratos P (eds) (2004) Emerging paradigms in international entrepreneurship. Edward Elgar Publishing Ltd, Northampton, Mass. and Cheltenham, UK, Fall 2004

Knight GA, Cavusgil ST (1996) The born global firm: a challenge to traditional internationalization theory. Advan Int Market 8:11-26

Knight GA, Cavusgil ST (2004) Innovation, organizational capabilities and the born-global firm. J Int Busin Stud 35(2):124-141

McKinsey (1993) Emerging exporters: Australia's high value-added manufacturing exporters. Australian Manufacturing Council, Melbourne

Oviatt BM, McDougall PP (1994) Toward a theory of international new ventures. J Int Busin Stud 25(1):45-64

Oviatt BM, McDougall PP (1995) Global start-ups: entrepreneurs on a worldwide stage. Acad Manag Execut 9(2):30-43

Rennie MW (1993) Global competitiveness: born global. McKins Quart 4(4):45-52

Scott WR (1987) The adolescence of institutional theory. Admin Sci Quart 32(4):493-511. (Dec., 1987). Also at Stable URL:http://links.jstor.org/sici?sici=0001

Tolbert PS, Zucker LG (1999) The institutionalization of institutional theory, Available at http://digitalcommons.ilr.cornell.edu/do/search/?q=Tolbert\&start=0\&context=160907

Welsh LS, Loustarinen RK (1993) Inward and outward connections in internationalization. J Int Market 1:46-58

Wright RW (ed) (1999) International entrepreneurship: globalization of emerging businesses. in AM Rugman's research in global strategic management. JAI Press, Stamford, Connecticut 